\title{
Working even harder in the fight against oral cancer
}

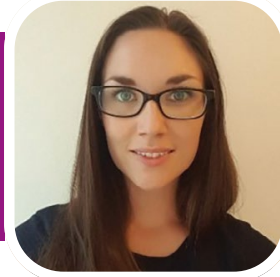

\author{
Kimberley Lloyd-Rees,' on behalf of \\ Tandex, explains how the pandemic \\ exacerbated an existing problem.
}

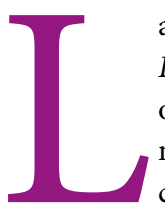

ast November, an article in BDJ In Practice considered the ongoing impact of the first national lockdown on oral cancer, citing 14 million missed dental appointments - and thus 'potentially thousands' of missed opportunities for early diagnosis - as well as the disruption to treatment for existing patients. ${ }^{1}$

As with so many health and social care issues, the pandemic didn't create a new problem, it exacerbated an existing one. The data show that, over the last decade, the number of people diagnosed with oral cancer annually has continued to rise, as have mortality rates. ${ }^{2}$ It can start on the lips, on or underneath the tongue, and includes a tumour found in any area of the mouth, head or neck, from the tonsils to salivary glands and oesophagus. All dental practitioners play an important role in improving patient awareness of the signs and symptoms of the disease, and the associated risk factors.

\section{The ever-present problem of access} The first - and perhaps most significant challenge is poor access to dental care, leading to a late diagnosis. This falls into the already present' problem list as, long before the pandemic, tens of thousands of people around the UK were already finding it impossible to get

\section{Author information}

'Kimberley graduated from the University of Sheffield in 2010, where she now works as a clinical tutor in Dental Hygiene and Therapy as well as working in practice. She has spent her career working across a variety of specialist private and mixed dental practices, for the MOD and volunteering her time to a dental charity in Nepal. an appointment with an NHS dentist, leading to talk of a system in 'crisis."

Although practices have been allowed to resume services for some time, whether NHS or private, many are still running with reduced capacity or are only able to provide emergency treatments. Even among patients for whom getting an appointment isn't difficult, there will almost certainly be some who need reassurance that it is safe to return. The message must be loud and clear - if they feel or see something unusual in their mouth, neck or head area, they should contact the practice without delay. In every suspected case of oral cancer, a patient's prognosis is greatly improved if it is caught early, so time is of the essence. If they are a smoker, or in one of the other high-risk groups, prompt action is particularly important. ${ }^{4}$ Most abnormalities will be harmless, which is why they must have them checked.

\section{Knowledge and awareness are key} The key, as always, is positive engagement. A challenge for all health practitioners post-Covid is 'message fatigue' - patients zoning out from being constantly told what to do - so effective delivery is crucial. ${ }^{1}$ Your website and social media will likely be your most useful resource for the foreseeable future, as people are not spending time in waiting areas to read a poster or pick up a leaflet. Be positive and make the goal to promote knowledge and understanding. The Oral Health Foundation has self-check resources on its website, which you could link to. But alongside any list of symptoms must be a disclaimer that anything that is giving cause for concern is a good enough reason to talk with an oral health practitioner.

Include information on risk factors too. All smokers know their habit is not good for their health, but they might not know that if they smoke and drink alcohol this substantially increases their risk of developing oral cancer. ${ }^{4}$ Taken as an individual risk factor, drinking alcohol to excess is also linked to cancers of the head and neck - the article includes evidence to indicate that people drank more during the pandemic, with heavy drinkers increasing the amount they drank. ${ }^{1}$ Other risk factors include subtypes of the human papillomavirus (HPV), also a poor diet, age and gender - most new cases occur in men over the age of $55 .^{2}$ It's not enough to simply list these risk factors and expect patients to absorb the information though; the whole topic of HPV warrants a detailed discussion in itself.

So, although tailored web-based resources are a good starting point, oral cancer should be a key topic for your oral health consultations, as you can cover so many relevant areas, from smoking cessation to healthy eating. Dental hygienists and dental therapists are particularly well-placed to raise oral cancer awareness, as a patient might feel more comfortable discussing their smoking habit, than they would if they were speaking with a dentist. Also, cover daily hygiene practises, such as brushing technique and how to clean interdentally with a highquality interdental brush, such as the products from TANDEX, which tend to be easier to master than string floss. Keeping the mouth hygienically clean and healthy is essential for avoiding any kind of oral disease.

The pandemic has presented new challenges for the fight against oral cancer, but we must use the situation we find ourselves in as an opportunity to work even harder. Dentistry has always been full of passionate people who want to make a difference and now, as we move forward, our collective commitment to improving that nation's oral health is stronger than ever.

For more information on Tandex's range of products, visit https://tandex.dk/.

\section{References}

1. Oral cancer: A ticking time bomb? $B D J$ In Practice 2020; 33: 14-18. Available at: https://doi.org/10.1038/s41404-020-0561-y (accessed December 2020).

2. Oral Health Foundation. State of Mouth Cancer UK Report 2020/2021. Available at: https://www.dentalhealth. org/thestateofmouthcancer (accessed December 2020).

3. NHS Dental Statistics for England 201819, Annual Report, published 29 August 2020. Available at: https://digital.nhs. uk/data-and-information/publications/ statistical/nhs-dental-statistics/2018-19annual-report-pas (accessed December 2020).

4. NHS. Causes of mouth cancer. Available at: https://www.nhs.uk/conditions/mouthcancer/causes/ (accessed December 2020).

https://doi.org/10.1038/s41407-021-0528-9 